\title{
COLLECTING FOSSILS: AN AMATEUR'S PERSPECTIVE
}

LOUD, George A., Lorusso \& Loud, 745 South 23rd St., Arlington, VA 22202, U.S.A.

The American Federation of Mineralogical Societies (AFMS) is a national organization of rockhound clubs. The AMFS formed the American Lands Access Association (ALAA), "to promote and ensure the right of amateur collecting and recreational mining, and the use of public and private lands for educational and recreational purposes."

The Fossil Preservation Act of 1996 addresses several problems. Firstly, it would provide a single statutory authority, applicable to all federal lands, defining for the amateur, and all fossil collectors, a line of demarcation between what is legal and what is illegal with respect to fossil collecting on public lands. Secondly, it would establish that most federal lands should be open to fossil collecting and would place the burden on a land manager to justify the closing of a designated area to non-permitted collecting, through a rule-making procedure including notice published in the Federal Register. Thirdly, the proposed legislation would extend the right of amateur collectors to surface collecting of both vertebrate and invertebrate fossils on those lands open to such collecting. One advantage that the proposed legislation offers the scientific community is that it would provide statutory guidelines, "universally" applicable to federal lands, for permitting of collecting activities which would go beyond the scope of "surface" collecting and amount to what the Fossil Preservation Act of 1996 referred to as "quarrying."

To the extent that the provisions of the proposed 1996 legislation relating to vertebrate fossil collecting by amateurs might be an area of contention, I quote John Pojeta "Not all vertebrate fossils are rare and not every scrap of bone or tooth is a scientific icon." The contributions of amateurs to vertebrate paleontology have been many. According to the brochure prepared for the 1995 T-Rex exhibit in Japan, of 19 known skeletons of T-Rex (to April 1995), 14 were discovered by amateurs, 4 by professional collectors, and 1 by a degreed paleontologist. With one or two exceptions, all of these are currently on exhibit in public museums. Another well-known contribution of amateurs was their involvement in the 1979 discovery of the duckbill dinosaur nesting grounds by Jack Horner. The clue that led Jack to that discovery was a fossil collected by an amateur, which Jack found in a rock shop.

Proponents of the 1996 Act argue that a fossil once exposed at the surface will eventually be lost to erosion, if it is not collected. They hold that amateurs are an essential resource to minimize such losses. Opponents of the 1996 Act, or of some of the aspects of the bill, believe that the concern with regard to loss of fossils to erosion is vastly overblown. In my opinion, both sides should acknowledge that higher levels of amateur collecting would accelerate the pace of discovery and accelerate the growth of our knowledge of life's history on Earth. Furthermore, amateur collecting contributes to our society at large, to the extent that for many young people it provides the first spark of interest in science. 